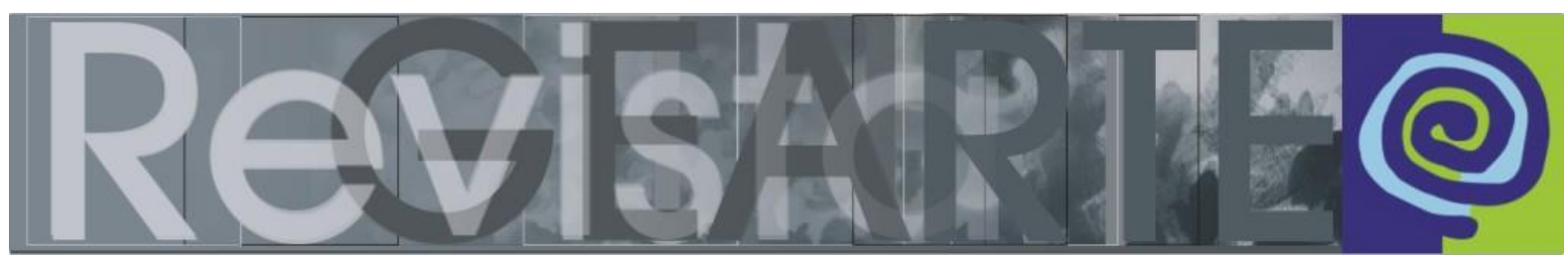

e-ISSN 2357-9854

\title{
Relações intertextuais e sentidos dialógicos
}

\author{
Luzinete Carpin Niedzieluk (Universidade do Estado de \\ Santa Catarina - UDESC, Florianópolis/SC, Brasil) \\ Sandra Ramalho e Oliveira (Universidade do Estado de \\ Santa Catarina - UDESC, Florianópolis/SC, Brasil)
}

\begin{abstract}
RESUMO - Relações intertextuais e sentidos dialógicos - O objetivo deste trabalho é identificar como os textos sincréticos ou multimodais dialogam em si mesmos para produzir sentidos, apontando tanto movimentos dialógicos de aproximação, como os sentidos gerados nos espaços intervalares hiatos, isto é, as complexas relações intertextuais ou interdiscursivas instauradas entre textos de linguagens estéticas distintas. Apresenta-se uma breve revisão bibliográfica sobre conceitos que fundamentam a pesquisa como texto, enunciado, discurso, dialogismo, intertextualidade, interdiscursividade, polifonia, multimodalidade, sincretismo, hiato de acordo com autores como Bakhtin e Volochinov (1999), Kristeva (1974), Fiorin (1994); Landowski (2004), Ramalho e Oliveira (2016). A metodologia é qualitativa, descritiva e dialógica; o objeto empírico analisado é uma tira de histórias em quadrinhos. Como resultados, apontam-se efeitos de sentido gerados a partir das relações dialógicas e dos hiatos.
\end{abstract}

PALAVRAS-CHAVE

Dialogismo. Intertextualidade. Hiato. Textos Sincréticos.

ABSTRACT - Intertextual relationships and dialogical senses - The aim of this work is to identify how the syncretic or multimodal texts dialogue within themselves to produce meanings, indicating both the dialogical movements of approximation and meanings generated in the intervallic spaces - hiatus, that is to say, the complex intertextual or interdiscursive relations established between texts of different aesthetic languages. A brief bibliographic review present the concepts that are the basis of the research such as text, enunciation, discourse, dialogism, intertextuality, interdiscursivity, polyphony, multimodality, syncretism, hiatus, according to authors as Bakhtin and Volochinov (1999), Kristeva (1974), Fiorin (1994), Landowski (2004), Ramalho e Oliveira (2016). The methodology is qualitative, descriptive and dialogical; the analyzed empirical object is a comic strip. As results, we point out the effects of meaning generated from the dialogic relations and hiatus.

\section{KEYWORDS}

Dialogism. Intertextuality. Hiatus. Syncretic Texts.

\section{Situando esta fala}

Nosso objeto de estudo consiste em apontar relações de sentido em textos sincréticos, multimodais ou verbo-visuais, por meio das relações dialógicas nos hiatos, espaços intervalares imanentes em fenômenos dessa natureza.

As orientações teóricas que nortearam este texto fundamentam-se em estudiosos de textos em amplo espectro, destacando-se Bakhtin (2002a; 2002b; 
2002c); Bakhtin e Volochinov (1999); Kristeva (1974); Alpízar (2003); Fiorin (1994), Kress e van Leeuween (2006), Landowski (2004), Ramalho e Oliveira (2016), os quais oferecem subsídios para a tarefa de se tentar entender como os textos, especialmente os verbo-visuais, sincréticos ou multimodais dialogam entre si para promover a produção de sentidos. Para tanto, levar-se-á em conta os movimentos dialógicos visando observar onde os sentidos são gerados, ou seja, se eles se dão em espaços intervalares - hiatos, isto é, se há um espaço, imaginário, virtual ou físico, onde se dão as complexas relações intertextuais ou interdiscursivas instauradas entre textos, imagens ou gêneros da esfera estética, artística ou não.

Para tanto, estruturamos este trabalho primeiramente apresentando os conceitos basilares que nos fundamentam como intertextualidade, interdiscursividade, dialogismo, polifonia, multimodalidade, sincretismo e hiato. A partir da definição desses fenômenos de linguagem, em um segundo momento, busca-se apontar efeitos de sentido no texto verbo-visual, sincrético, multimodal; uma tira de História em Quadrinhos (doravante, HQs) - da série intitulada Armandinho, de autoria de Alexandre Beck, examinando suas relações dialógicas intertextuais ou interdiscursivas como também os possíveis sentidos dialógicos passíveis de serem construídos nos hiatos. Finalizamos com as referências.

\section{Texto, Enunciado, Discurso}

É relevante mencionar que nesta pesquisa consideramos como texto não apenas os verbais, mas também os visuais, os sonoros, os híbridos ou sincréticos ou multimodais.

Sabemos que os conceitos de signo e de texto estão sendo revistos, mas para uma compreensão histórica dos fenômenos de significação, é necessário revisitá-los. Segundo J. Fontanille (2009, p. 45), para a semiótica, em um primeiro momento, tudo era signo, e depois, para a semiótica discursiva tudo era texto, o que prestou grande serviço à disciplina, em termos de delimitação dos objetos; entretanto, o fato é que existem fenômenos "intertextualizáveis", ainda que texto seja tomado como uma metáfora. Contudo, segue o autor (2009, p. 47) dizendo que mesmo correndo riscos, 
a semiótica discursiva continua analisando textos, imagens, filmes, práticas, situações, entre outros fenômenos de significação e de sentido.

Antes de conceituarmos texto, considerado enunciado, precisamos evidenciar que na abordagem dialógica da linguagem proposta por Bakhtin e Volochinov (1999) um dos elementos-chave é a palavra do outro, uma vez que na linguagem viva, cada palavra é compreendida como signo sócio-ideológico; é como que o resultado de uma relação de força entre o eu e outro, numa tensão que se manifesta tanto no tema, como na forma e no conteúdo.

Ao se referir ao signo, Bakhtin e Volochinov (1999) afirmam "tudo o que é ideológico é um signo. Sem signos não existe ideologia”, ou seja, o domínio do ideológico coincide com o domínio dos signos, sendo mutuamente correspondentes: "tudo que é ideológico possui um valor semiótico"; com isso, todo signo está sujeito aos critérios da avaliação ideológica. (BAKHTIN; VOLOCHINOV, 1999, p. 31-32, grifo dos autores). Assim, a ideologia determina a linguagem, e o texto é sempre um acontecimento de natureza social.

Quanto à concepção de texto, para Bakhtin (2002a, p. 295-296)

Todo texto posee un sujeto que es el autor (hablante o escritor). [...]. Hay dos momentos que determinan un texto como enunciado: su proyecto (intención) e la realización de éste. Las inter-relaciones dinámicas entre estos momentos, la lucha entre ellos, que determina el carácter del texto". [...]. Cada texto (visto como enunciado) es algo individual, único e irrepetible, en lo cual consiste todo su sentido (su proyecto, aquello para que se había creado el texto).

Enunciado, entendido como texto, representa um elo na cadeia complexa e contínua da comunicação discursiva. Todo enunciado tem como traço fundamental o fato de que já é resposta a outros enunciados. É um elo da cadeia dos atos de fala; portanto, não pode ser nem o primeiro nem o último, pois há os já-ditos (enunciados históricos), e, em seu horizonte, também estão os enunciados que o seguem (enunciados futuros), isto é, os enunciados estão ligados entre si, na comunicação discursiva, por relações dialógicas. Com isso, o discurso é dialógico, dirigido ao outro participante da interação verbal e conta com a compreensão ativa do ouvinte. 
Segundo Bakhtin (2002c, p. 89) "todo discurso é orientado para resposta e ele não pode esquivar-se à influência profunda do discurso da resposta antecipada". Tanto os enunciados como os discursos são acontecimentos sociais de natureza dialógica.

O enunciado ou texto é o elo que liga o locutor ao interlocutor, e há um vínculo entre o enunciado e a situação social, ou seja, a situação constitui-se em uma parte do enunciado, indispensável para a compreensão do seu sentido. Tanto o enunciado quanto o discurso são interpretados como acontecimentos sociais de natureza dialógica.

O enunciado, entendido como texto "é o produto da interação de dois indivíduos socialmente organizados e, mesmo que não haja um interlocutor real, este pode ser substituído pelo representante médio do grupo social ao qual pertence o locutor" (BAKHTIN; VOLOCHINOV, 1999, p. 112). Segundo os autores, a palavra se orienta em função de um interlocutor e, consequentemente, ela comporta duas faces: é determinada pelo fato de que procede de alguém e pelo fato de que se dirige para alguém, constituindo o produto da interação do locutor e do ouvinte.

Assim, todo enunciado é parte integrante de um diálogo ininterrupto, como uma voz que traz em si a perspectiva da voz do outro, o ponto de vista do outro, a entonação expressiva (tom ou acento valorativo) alheia. O nosso discurso (oral ou escrito) nunca é totalmente "inédito", pois traz ecos de outros discursos, ou seja, discursos de outrem, reorganizados dialogicamente nas falas dos sujeitos, podendo aparecer mais explicitamente marcados pelos recursos linguísticos (utilizados estilisticamente pelos falantes), como no discurso direto, ou de maneira "diluída" e menos marcada, como ocorre no discurso indireto e indireto livre.

Compreender é um processo ativo, é fazer das palavras do outro, a nossa palavra, assim, a nossa voz é hibrida por natureza e para Bakhtin só o Adão mítico diante de um mundo virgem, poderia evitar a dialogização. 


\title{
Dialogismo, polifonia e bivocalidade
}

Dialogismo no sentido bakhtiniano, são as diferentes vozes instauradas nos enunciados, discursos. Polifonia assim como heteroglossia são apenas outros termos para dialogismo, pois na década de 30, Bakhtin concebe a linguagem como heteroglossia, ou seja, como um conjunto múltiplo e heterogêneo de vozes ou línguas sociais, isto é, um conjunto de formações verbo-axiológicas. Também chamado de plurilinguismo, (o discurso de outrem na linguagem de outrem, cuja palavra deste discurso/texto é bivocal) lembrando que os textos originais estavam escritos em russo e houve dificuldades em função das traduções, por isso, palavras nem sempre coincidem com as palavras estabelecidas pelo autor.

Para Bakhtin, (2002b, p. 195):

\begin{abstract}
As palavras do outro, introduzidas na nossa fala, são revestidas inevitavelmente de algo novo, da nossa compreensão e da nossa avaliação, isto é, tornam-se bivocais. [...]. O nosso discurso da vida prática está cheio de palavras dos outros. Com algumas delas fundimos inteiramente a nossa voz, esquecendo-nos de quem são; com outras reforçamos as nossas próprias palavras, aceitando aquelas como autorizadas para nós; por último, revestimos terceiras das nossas próprias intenções, que são estranhas e hostis a elas.
\end{abstract}

$\mathrm{Na}$ dialogia as vozes estão presentes, as entonações (valorações verboaxiológicas pessoais) são fundamentais, valoram e ideologizam, as palavras e as réplicas são vivas, e as consciências estão em interação.

Um exemplo de discurso polifônico ou bivocal é a ironia, nela a palavra tem duplo sentido: volta-se para o objeto do discurso como palavra comum e para um outro discurso. Esta segunda voz entra em hostilidade (contradição) com a primeira e o discurso se converte em palco de luta entre duas vozes (a voz do parodiado e do parodiante - zomba-se da voz séria e, ao mesmo tempo afirma-se uma alegria com a outra voz). Bakhtin destacou o papel do dialogismo na sua construção, cujo resultado ele chamou "híbrido premeditado". Com isto, referia-se à inseparabilidade da essência da paródia que, ao mesmo tempo em que dialoga propositalmente com o texto parodiado, não se confunde com ele. 
Para Braith, (2005, p.80), “[...] o dialogismo é um elemento constitutivo da linguagem, esse princípio que rege a produção e compreensão dos sentidos, essa fronteira em que o eu e o outro se interdefinem, se interpenetram, sem se fundirem ou se confundirem"; nesse sentido, dialogismo é um jogo dramático de vozes e a condição de sentido do discurso, enunciado ou texto.

Estudiosos de Bakhtin, entre eles, Fiorin (2014) e Barros (1996) afirmam que o dialogismo se dá das seguintes formas: a) Todo enunciado apresenta duas posições: a sua e aquela em oposição à qual ela se constrói e b) Em todo enunciado há a incorporação pelo enunciador da voz ou das vozes de outro(s), e esta incorporação é mostrada pela forma composicional do próprio enunciado por meio de recursos linguísticos como o uso de aspas, ou de negação. São exemplos, o discurso relatado direto, o discurso relatado indireto e o discurso bivocal, considerados como formas de dialogismo interno, das vozes que falam e polemizam no texto, no enunciado reproduzindo o diálogo com outros textos, com outros enunciados, mostrando que a polifonia é a forma suprema do dialogismo.

\section{Intertextualidade, Interdiscursividade}

É sabido que o conceito de intertextualidade foi proposto por Kristeva, em um artigo publicado na Revista Critique intitulado "Bakhtine, le mot, le dialogue, le roman" em 1967. A pesquisadora sugere que a intertextualidade deva ser compreendida como o diálogo entre textos distintos em que um texto retoma outro texto. Para ela, "[...] todo texto se constrói como mosaico de citações, todo texto é absorção e transformação de um outro texto." (KRISTEVA, 1974, p. 64).

Segundo Alpízar (2003, grifos do autor, p. 137), "El término intertextual hace referencia a una relación de reciprocidad entre los textos, es decir, a una relación entre-ellos, en un espacio que trasciende el texto como unidad cerrada".

Este mesmo autor (2003, p.138), traz a concepção de texto de Barthes: todo texto es una "câmara de ecos" e a interpreta da seguinte maneira:

Ser una 'cámara de ecos' es, precisamente ser la caja de resonancia de diversos discursos, sin estar en la obligación de asumir con maestría ninguno 
de ellos. [...]. La intertextualidad es precisamente la imposibilidad de asumir ningún texto con maestría.

Para o linguista e semioticista Fiorin, (1994, p. 30), há uma diferença entre intertextualidade e interdiscursividade: "A intertextualidade é o processo e incorporação de um texto em outro, seja para reproduzir o sentido incorporado, seja para transformá-lo" e "A interdiscursividade é o processo em que se incorporam percursos temáticos e/ou percursos figurativos, temas e/ou figuras de um discurso em outro." (p. 32).

Barros (1996, p. 24), recorre a teoria bakhtiniana e define texto como dialógico; para autora "[...] o texto é constitutivamente dialógico; define-se pelo diálogo entre os interlocutores e pelo diálogo com outros textos (da situação e da enunciação) e só assim, dialogicamente, constrói-se a significação." Segundo a autora, a intertextualidade na obra de Bakhtin é intertextualidade "interna" das vozes que falam e polemizam no texto, nele reproduzindo o diálogo com outros textos". (2011, p. 04) Esta autora, ao referir-se "a diálogo com outros textos", lembra o que Kristeva, após leituras bakhtinianas, denomina intertextualidade. Para os estudiosos de Bakhtin, entre eles destacamos Barros (1996) e Brait (1997; 2005), o termo dialogismo é considerado o princípio constitutivo da linguagem, e este tem vários aparentados como intertextualidade ou interdiscursividade, ou bivocalidade, ou ainda polifonia, assim percebe-se em todas estas concepções de intertextualidade, das relações entre textos, ecos do dialogismo bakhtiniano.

Nesta pesquisa, optamos por usar o termo intertextualidade e ou interdiscursividade como sinônimos, pois entendemos assim como proposto por Bakhtin no seu livro Marxismo e Filosofia da Linguagem (1999), que o princípio constitutivo da linguagem, da palavra é a interação, a dialogia, a intertextualidade ou a interdiscursividade. Parafraseando Brait (1997), a natureza dialógica da linguagem é um conceito fundamental é a célula geradora do pensamento bakhtiniano, isto é, Bakhtin concebe o eu e o outro como inseparavelmente ligados e tendo como elemento articulador a linguagem. 


\section{Textos multimodais, sincréticos}

Um texto multimodal pode ser descrito como um texto que incorpora mais de uma modalidade de linguagem que realiza comunicação por meio de mais de um código semiótico. (KRESS; VAN LEEUWEN, 2006). A denominação de texto multimodal vai ao encontro do que Calabrese (2008) denomina de "semióticas sincréticas", quando as linguagens se associam, se mesclam.

A multimodalidade é entendida, em termos gerais, como a co-presença de vários modos de linguagem, sendo que os modos interagem na construção dos significados da comunicação social. Essa perspectiva se apoia no argumento de que a comunicação humana é essencialmente multimodal, pelo fato de que os modos semióticos não funcionam separadamente, mas em uma interação, todos realizando os significados que fazem parte de seu potencial semiótico (Kress, van Leeuwen, 2006).

A multimodalidade envolve o estudo de textos verbais conectados a outros modos semióticos como visual, sonoro, gestos e movimento para mostrar que a significação nos textos é representada de diferentes formas. Embora diferentes modos semióticos possam se conectar com o modo verbal, estes não dependem do verbal, como também o verbal não depende de outros modos semióticos (KRESS e van LEEUWEN, 2006, p. 17). Na construção de sentidos, os modos semióticos se integram, possibilitando-nos afirmar que todo texto é multimodal.

\section{A relação entre hiato e dialogismo}

Ramalho e Oliveira (2016, p.111) ancorada nos estudos de S. Rabeau (2002) e O. Calabrese (2008) traz a concepção de hiato ou intervalo que é considerado:

[...] espaço intervalar privilegiado para a criação, o espaço de trabalho do tradutor de textos ou imagens, o locus de trans-formações de formas e ideias, originando outras; é o espaço entre o que já existe e o que irá existir. Ou seja, é o espaço de tempo e o(s) local(is) onde habitam o ilustrador, o fotógrafo, o estilista, o publicitário, o escritor, o cineasta, o compositor, o dramaturgo, o artista visual, o designer, desempenhando atividades e gerando processos cujos resultados fazem com que eles sejam reconhecidos socialmente pelo que fazem e que possam ser considerados como profissionais, estilistas, publicitários ou designers. 
Esta concepção de hiato entendida como espaço de tempo e o local onde se "encontram" os sentidos, aqueles produzidos pelos sujeitos que criam e aqueles em negociação com os sujeitos que recriam, transformam textos ou imagens, mostrando a dialogicidade interna, a intertextualidade ou intratextualidade, "o discurso de outrem na linguagem de outrem" que funciona como "uma amalgama química (no plano de sentido e da expressão); o grau de influência mútua do diálogo pode ser imenso." (Bakhtin, 2002c, p. 127 e 141), isto é, há muitos sentidos gerados nestes espaços intervalares que revelam as atitudes dialógicas dos sujeitos sócio-históricos.

A noção de hiato proposta por Ramalho e Oliveira pode ser relacionada a noção de cronotopo bakhtiniana, "o processo de assimilação do tempo, do espaço, e do indivíduo histórico real que se revela neles" (Bakhtin, 2002c, p. 211), ou seja este é o espaço onde se produz significação, está em constante interação entre o que já existe e o que irá existir, e onde está em constante diálogo, [é um espaço da dimensão do contexto de produção é extraverbal] isto é, não se revela explicitamente no produto final, é o lugar social e histórico de onde o criador (artista, designer etc.) gera seu projeto intertextual que o faz ser reconhecido, seu ethos, entendido como a "impressão que o criador/produtor, por sua criação, dá de si mesmo"; é o seu estilo, aquilo que o identifica.

Ramalho e Oliveira (2016, p. 113), assim como Calabrese (2008) propõem que o "estudo dos espaços entre, entre palavras, entre imagens, entre textos, entre o que é e o retratado, entre o que há e o devir, são primordiais" para que possamos compreender que o mérito de uma criação não está no texto de saída, mas sim na fidedignidade do texto de chegada, na transformação que o criador, designer ou outro conseguiram, gerando sentidos variados, no hiato entre textos, a partir dos planos de expressão e do plano de conteúdo para com o texto original.

\section{Um texto sincrético e algumas considerações}

Mostraremos a seguir, na linguagem considerada sincrética pela semiótica discursiva e denominada de gênero multimodal pela semiótica social de Kress e van Leuween, uma História em Quadrinhos (doravante, HQs) - da série denominada 
Armandinho, de autoria de Alexandre Beck, as relações dialógicas intertextuais ou interdiscursivas ou ainda intratextuais e intradiscursivas, como também os possíveis sentidos dialógicos processados nos hiatos, ou seja, nos espaços intervalares. O fato de se oferecer a opção de denominá-las 'intra', além de intertextualidade, vem das reflexões de Barros (1996, p. 24), quando afirma que a intertextualidade na obra de Bakhtin é intertextualidade "interna" das vozes que falam; ora, por que não chamá-la de intratextualidade, essa intertextualidade "interna"?

\section{Figura 1 - História em Quadrinhos}

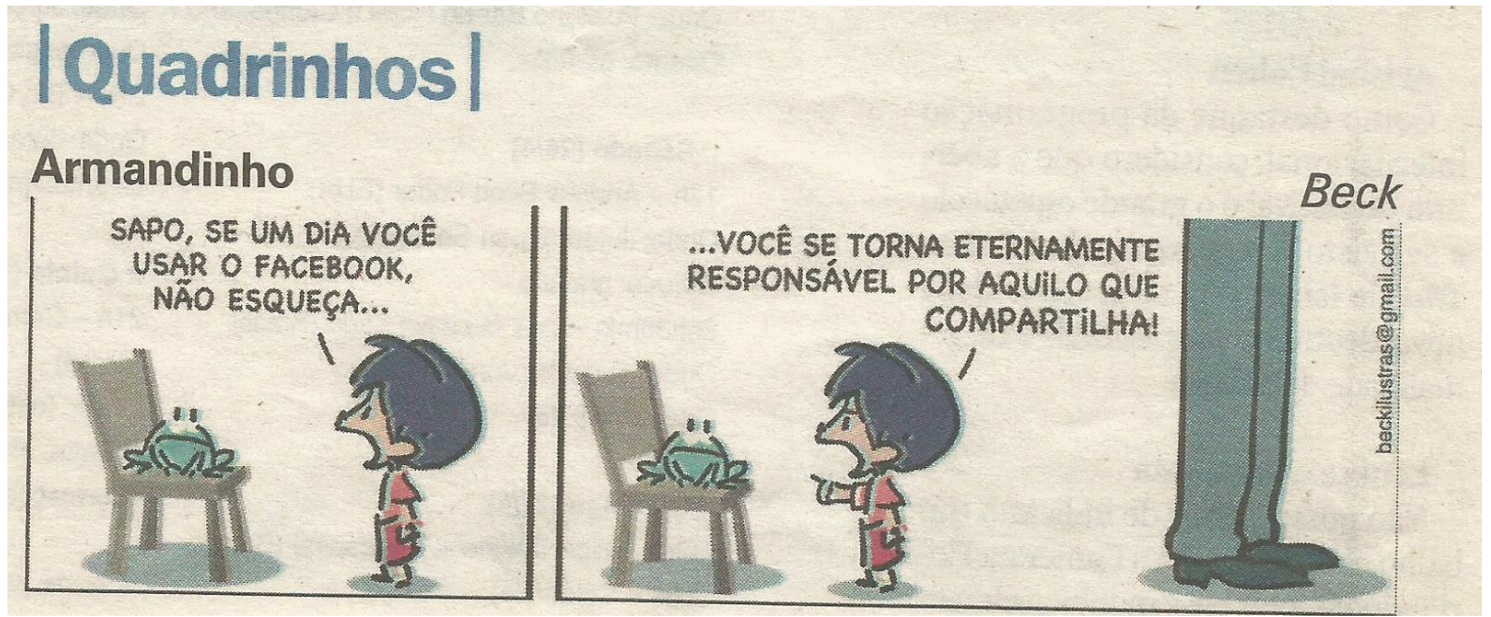

Fonte: Diário Catarinense (19/04/2014).

É relevante mencionar que HQs, como se trata de um texto constituído por duas linguagens, pode ser considerada linguagem sincrética ou verbo-visual, ou ainda multimodal, isto é, composta pela linguagem verbal (sequências verbais) e pela nãoverbal (os desenhos, os requadros - espécie de "moldura" para as cenas desenhadas -, e pelos hiatos - espaços intervalares nos requadros -, o letreiramento - o tipo de fonte usada -, a perspectiva e o plano ou enquadramento, etc.), e estamos as considerando articuladas, interatuantes, a partir de um projeto "gráfico", isto é de um projeto discursivo de seu autor.

A HQs analisada foi publicada no Diário Catarinense em 19/04/2014; vale ressaltar que é direcionada a um tipo de público, cuja finalidade do veículo é informar e entreter.

Na perspectiva bakhtiniana, ao analisarmos um texto devemos levar em conta, além da sua constituição verbal, também aspectos da dimensão extraverbal, isto é, 
observar no texto, marcas de um sujeito, de um lugar histórico e social, de uma posição discursiva que circula entre textos e faz circular textos.

Para isso, devemos inicialmente, ao nos deparar com um texto, fazer indagações a ele, como, por exemplo: “A quem se dirige este texto/enunciado?", "Como o locutor percebe e imagina seu destinatário?", “Onde e quando foi publicado?", "Qual o papel social do destinatário sobre o texto?"

É claro que outras abordagens, métodos e teorias podem propor entradas diferentes nos textos visuais, verbais, sonoros, híbridos, sincréticos ou verbo-visuais, mas aqui estamos revisitando principalmente conceitos bakhtinianos e trazendo para nosso cotidiano.

Por exemplo, se de um lado, as proposições de Landowski (2004) afirmam que sentidos se negociam na interlocução entre dois polos da enunciação, isto é entre enunciador e destinatário, Bakhtin propõe que o enunciado seja o elo que liga o locutor ao interlocutor, mas há um vínculo entre o enunciado e a situação social, ou seja, a situação constitui-se em uma parte do enunciado, indispensável para a compreensão do seu sentido. Portanto, na perspectiva bakhtiniana, os sentidos constituem o produto da interação do locutor e do ouvinte, são determinados pelo fato de que procedem de alguém e se dirigem para alguém.

Bakhtin parte do pressuposto de que o sentido de um texto ou de um enunciado está no projeto discursivo do autor e na realização deste projeto, desta forma, vê-se nesta HQs, que a proposta de seu autor, Beck traz explicitamente a noção de dialogismo intertextual bakhtiniano ou a noção de intertextualidade de Kristeva e também de demais autores acima citados, pois faz referência ao livro $O$ Pequeno Príncipe (2015, p. 51) de Saint Exupéry, publicado pela primeira vez, em 1943, nos Estados Unidos, especificamente no diálogo do principezinho com a raposa, transcrito, a seguir:

A raposa então calou-se e considerou muito tempo o príncipe:

- Por favor, cativa-me! Disse ela.

- Bem quisera, disse o príncipe, mas eu não tenho tempo. Tenho amigos a descobrir e mundos a conhecer. 


\begin{abstract}
- A gente só conhece bem as coisas que cativou, disse a raposa. Os homens não têm tempo de conhecer coisa alguma. Compram tudo prontinho nas lojas. Mas como não existem lojas de amigos, os homens não têm mais amigos. Se tu queres uma amiga, cativa-me!

Os homens esqueceram a verdade, disse a raposa.

Mas tu não a deves esquecer.

Tu te tornas eternamente responsável por aquilo que cativas.
\end{abstract}

Além disto, Beck atualiza os efeitos de sentido atualizando a frase e ou enunciado no contexto atual, primeiramente pela troca do próprio gênero, pois o original um livro, e o atual HQs; acrescentando ao diálogo entre seus personagens sapo e Armandinho, a mídia contemporânea - o Facebook, que em 1943 não existia. Vemos também, a dialogicidade interna, a forma como Beck incorpora o discurso de Saint Exupéry no seu próprio discurso.

Outro aspecto a considerar é a forma como o autor-criador desloca este texto do livro já por si valorado, por um ato axiológico, para o interior de outro texto de outro enunciado concreto (HQs). Esta posição do autor é considerada nos termos bakhtinianos refratada (se trata de uma posição axiológica conforme recortada pelo viés valorativo do autor-pessoa) e refratante (é a partir desta posição que se recortam e reordenam esteticamente os eventos da vida). Isto é, o sentido dos textos, são sempre diferentes, pois deve-se levar em conta seus participantes (autor-criador e interlocutores), seu cronotopo (tempo e espaço), as condições de produção, de recepção e de circulação.

Isso corrobora o que Ramalho e Oliveira afirma como hiato: "o processo de assimilação do tempo, do espaço, e do indivíduo histórico real que se revela neles" (2002, p. 211), este espaço intervalar, este locus de criação do autor-criador é primordial, pois é um lugar de elaboração e de transformação de ideias, bem como gerador de efeitos de sentidos diferentes, conforme mostrado na análise, pois o texto em sua forma original (livro) foi pensado para um determinado público, para uma determinada forma organizacional (livro), para o espaço e tempo em que foi publicado, para leitores presumidos etc., totalmente diferentes da HQs analisada. Por isso, a importância de se levar em consideração a dimensão extraverbal (tema, forma composicional e estilo) nos textos, para além de sua forma verbo-visual. 


\section{Referências}

ALPÍZAR, Iván Villalobos. La noción de intertextualidad en Kristeva y Barthes. Rev. Filosofía Univ. Costa Rica, XLI (103), Enero-Junio 2003, p.137-145.

BAKHTIN, Mikhail. Estética de la creación verbal. Trad. Tatiana Bubnova. 1. ed. Buenos Aires: Siglo XXI Editores Argentina, 2002a [1979].

BAKHTIN, Mikhail. Problemas da poética de Dostoiévski. Trad. Paulo Bezerra. 3. ed. Rio de Janeiro: Forense Universitária, 2002b [1929].

BAKHTIN, Mikhail. Questões de literatura e de estética. A teoria do romance. 5. ed. São Paulo: Annablume Editora, 2002c [1975].

BAKHTIN, Mikhail; VOLOCHINOV, Valentin. Marxismo e filosofia da linguagem. Trad. Michel Lahud e Yara F. Vieira. 9. ed. São Paulo: Hucitec, 1999 [1929].

BARROS, Diana Luz Pessoa de. Contribuições de Bakhtin às teorias do texto e do discurso. In: FARACO, Carlos Alberto; TEZZA, Cristovão, CASTRO, Gilberto de. (Orgs.). Diálogos com Bakhtin. Curitiba: Ed. da UFPR, 1996. p. 21-40.

BARROS, Diana Luz Pessoa de. Dialogismo, polifonia e enunciação. In: Diana Luz Pessoa de; FIORIN, José Luiz. (Orgs.). Dialogismo, Polifonia, Intertextualidade: Em torno de Bakhtin Mikhail. São Paulo: Ed. da Universidade de São Paulo, 2011. p.01-09.

BRAIT, Beth. Bakhtin e a natureza constitutivamente dialógica da linguagem. In: BRAIT, Beth (Org.). Bakhtin, dialogismo e construção de sentido. Campinas, SP: Ed. Unicamp, 1997

BRAIT, Beth. Estilo. In: BRAIT, Beth. (Org.). Bakhtin: conceitos-chave. São Paulo: Contexto, 2005, p. 79-102

BRAIT, Beth. As vozes bakhtinianas e o diálogo inconcluso. In: Diana Luz Pessoa de; FIORIN, José Luiz. (Orgs.). Dialogismo, Polifonia, Intertextualidade: Em torno de Bakhtin Mikhail. São Paulo: Ed. da Universidade de São Paulo, 1994. p.11-27

CALABRESE, O. Fra parole e imagine: metodologie ed esempi di analisi. Milano: Mondadori, 2008.

FIORIN, JOSÉ Luiz. Polifonia Textual e Discursiva. In: BARROS, Diana Luz Pessoa de; FIORIN, José Luiz. (Orgs.). Dialogismo, Polifonia, Intertextualidade: Em torno de Bakhtin Mikhail. São Paulo: Ed. da Universidade de São Paulo, 1994, p. 29-36.

FIORIN, JOSÉ Luiz. Interdiscursividade e intertextualidade. In: BRAITH, Beth (org.). Bakhtin: conceitoschave. 2. ed. 1 reimpressão. São Paulo: Contexto, 2014, p. 161-193.

FONTANILLE, Jacques. "Sémiotique de L'École de Paris - Introduction". In: ABLALI, Driss e DUCARD, Dominique. Vocabulaire des études sémiotiques et sémiologiques. Paris: Honoré Champion Éditeur; Besançon: Presses Universitaires de Franche-Comté, 2009, p. 43-48.

KRESS, G.; van LEEUWEN, T. Reading Images - The grammar of visual design. London: Routledge, 2006.

KRISTEVA, Julia. Introdução a semanálise. Trad. Lúcia Helena França Ferraz. São Paulo: Perspectiva, 1974 (Debates semióticos).

LANDOWSKI, Eric. Passions sans nom. Paris: PUF, 2004.

RABEAU, Sophie. L'Intertextualité. Paris: Flammarion, 2002.

RAMALHO E OLIVEIRA, Sandra. Intertextualidades: sentidos gerados nos espaços entre imagens distintas. In: RAMALHO E OLIVEIRA, Sandra; VANDRESEN, Monique; SCOZ, Murilo. (Orgs.). Desafios de Pesquisa em Design. Florianópolis: Ed. da UDESC, 2016, p. 89-115.

SAINT-EXUPÉRY, Antoine de. O Pequeno Príncipe. Rio de Jnaeiro: Agir, 2015. 


\section{Luzinete Carpin Niedzieluk}

Pós-doutoranda em Artes Visuais pelo Programa de Pós-Graduação em Artes Visuais - Centro de Artes, da Universidade do Estado de Santa Catarina (PPGAV/CEART/UDESC). Doutora em Linguística Aplicada pelo Programa de Pós-Graduação em Linguística (PPGL/UFSC). Membro do grupo de pesquisa CNPq Núcleo de Estudos Semióticos e Transdisciplinares - (NEST/UDESC). Mestre em Linguística Textual pelo Programa de Pós-Graduação em Linguística (PPGL/UFSC). Graduado em Licenciatura em Artes Visuais pela Universidade do Estado de Santa Catarina e em Licenciatura em Língua Portuguesa e Literaturas Universidade Federal de Santa Catarina.

E-mail: luzcarpin55@gmail.com

Currículo: http://lattes.cnpq.br/ 0576443782031097

\section{Sandra Ramalho e Oliveira}

Doutora em Comunicação e Semiótica pela PUC São Paulo (1998), com pós-doutoramento na França, em Semiótica Visual (2002). Pesquisadora e professora da Universidade do Estado de Santa Catarina/UDESC, atua na Graduação e no Mestrado em Artes Visuais como professora e orientadora. Autora dos livros Imagem também se lê, Moda também é texto, Sentidos à mesa e Diante de uma imagem, organizou, em coautoria, oito outros títulos de livros. Foi Coordenadora do PPGAV/UDESC, Presidente da ANPAP (2007-2008) e é consultora da CAPES.

E-mail: ramalho@floripa.com.br

Currículo: http://lattes.cnpq.br/0870589343786662 